\title{
Author Correction: Disordered grids in the third dimension
}

Dmitriy Aronov (D)

Correction to: Nature Neuroscience https://doi.org/10.1038/s41593-021-00925-2, published online 27 September 2021.

In the version of this News \& Views initially published, there was an error in ref. 1. The first author's name, Ginosar, was misspelt. The reference is corrected in the online version of the paper.

Published online: 14 October 2021

https://doi.org/10.1038/s41593-021-00959-6

๑) Springer Nature America, Inc. 2021

\section{Publisher Correction: Circuit and molecular architecture of a ventral hippocampal network}

Mark M. Gergues DD, Kasey J. Han, Hye Sun Choi, Brandon Brown, Kelsey J. Clausing (D), Victoria S. Turner, Ilia D. Vainchtein, Anna V. Molofsky iD and Mazen A. Kheirbek (D)

Correction to: Nature Neuroscience https://doi.org/10.1038/s41593-020-0705-8, published online 14 September 2020

In the version of this article initially published, the final parenthesis in the third equation in Methods was incorrectly placed before, instead of after, the superscript $R$. The error has been corrected in the HTML and PDF versions of the article.

Published online: 22 September 2021

https://doi.org/10.1038/s41593-021-00941-2

(c) The Author(s), under exclusive licence to Springer Nature America, Inc. 2021

\section{Publisher Correction: Brain mechanisms of compulsive alcohol use}

Shari Wiseman

Correction to: Nature Neuroscience https://doi.org/10.1038/s41593-021-00930-5, published online 29 September 2021.

In the version of this Research Highlight initially published, there was an error in the reference to the subject article (doi: 10.1126/sciadv. abg9045). The article appeared in Science Advances, rather than Science. The error has been corrected in the online version of the article.

Published online: 20 October 2021

https://oi.org/10.1038/s41593-021-00961-y

() Springer Nature America, Inc. 2021 